\title{
Effect of menopause on hormonal receptors in ampullae of the fallopian tube with a special reference to the $\mathrm{p} 53$ signature
}

This article was published in the following Dove Press journal:

International Journal of Women's Health

30 March 2017

Number of times this article has been viewed

\author{
Rie Urabe' \\ Toru Hachisuga' \\ Taeko Ueda' \\ Toshinori Kawagoe' \\ Tomoko Kurita' \\ Seiji Kagami' \\ Masanori Hisaoka ${ }^{2}$ \\ Yoshihisa Fujino ${ }^{3}$ \\ 'Department of Obstetrics \\ and Gynecology, ${ }^{2}$ Department \\ of Pathology and Oncology, \\ ${ }^{3}$ Department of Preventive Medicine \\ and Community Health, School of \\ Medicine, University of Occupational \\ and Environmental Health, Iseigaoka, \\ Yahatanishi-ku, Kitakyushu, Japan
}

Objectives: Age-related changes in the expression of hormonal receptors have not been well examined in the fallopian tube (FT). We herein report the effect of menopause on the hormone receptors in ampullae of the FTs (AFTs), in comparison with cortical inclusion cysts (CICs) of the ovary.

Methods: A total of 84 AFTs and 16 fimbriae of FTs, which were obtained from 26 premenopausal and 58 postmenopausal women; and 27 postmenopausal CICs were immunohistochemically studied for the expression of p53, Ki-67, estrogen receptor-alpha (ER- $\alpha$ ), and progesterone receptor A (PRA). Apoptotic cells were identified using a TUNEL assay.

Results: Postmenopausal AFTs showed a significantly lower labeling index (LI) for Ki-67 $(P<0.001)$, apoptosis $(P=0.03)$, and PRA $(P<0.001)$ than premenopausal AFTs. No significant correlation with immunohistochemical markers was found in premenopausal AFTs, but the LI for PRA was positively correlated with that for Ki-67 $(P=0.004)$ and inversely with that for p53 $(P=0.023)$ in postmenopausal AFTs. The expression of immunohistochemical markers was closely correlated between ampullae and fimbriae of the FT. The p53 signature (p53S) was detected in five postmenopausal AFTs (mean age: 70.2 years) and was not detected in any CICs. The immunohistochemical profile of p53S was low expression of Ki-67, apoptosis, and PRA, and high expression of ER- $\alpha$. The expression of PRA in CICs was significantly higher than that in AFTs $(P=0.001)$.

Conclusion: The expression of PRA was significantly lower in postmenopausal AFTs than in premenopausal AFTs, whereas the expression of PRA was well preserved in postmenopausal CICs.

Keywords: fallopian tube, progesterone receptor, estrogen receptor, p53 signature, apoptosis

\section{Introduction}

Although previous studies have investigated the expression patterns of estrogen receptor (ER) and progesterone receptor (PR) in human endometrium and documented both age-specific patterns of expression ${ }^{1,2}$ and hormone-dependent changes during the menstrual cycle, ${ }^{3,4}$ the expression of hormone receptors has not been well documented in the normal human fallopian tube (FT), especially the age-related expression of hormone receptors.

Recent morphologic and molecular genetic studies of women with a hereditary mutation in $B R C A 1$ and $B R C A 2$ have reported new findings regarding the carcinogenesis and histogenesis of pelvic serous carcinoma. ${ }^{5}$ It appears that a significant subset of pelvic serous carcinomas originates from the distal FT rather than the ovarian surface epithelium and/or ovarian cortical inclusion cyst (CIC). ${ }^{6}$ In addition, the p53
Correspondence: Toru Hachisuga Department of Obstetrics and Gynecology, School of Medicine, University of Occupational and Environmental Health, I-I, Iseigaoka, Yahatanishi-ku, Kitakyushu 807-8555, Japan

$\mathrm{Tel}+81936917449$

Fax +8193 6919337

Email thachisu@med.uoeh-u.ac.jp
International Journal of Women's Health 2017:9 I63-169

(c) (i) (8) 2017 Urabe et al. This work is published and licensed by Dove Medical Press Limited. The full terms of this license are avalable at https://www.dovepress.com/terms.ph (c) hereby accept the Terms. Non-commercial uses of the work are permitted without any further permission from Dove Medical Press Limited, provided the work is properly attributed. For permission for commercial use of this work, please see paragraphs 4.2 and 5 of our Terms (https://www.dovepress.com/terms.php). 
signature (p53S) is associated with serous tubal intraepithelial carcinoma (STIC) and has been reported to be the earliest lesion in the development of tubal serous carcinoma. ${ }^{\text {? }}$ Tone et al reported that the gene expression profiles of BRCA1/2-mutated FT during the luteal phase more closely resembled those of high-grade serous carcinomas than those of BRCA1/2-mutated FT during the follicular phase. ${ }^{8}$ They further suggested that studies of the relative PR isoform expression in FT exhibiting p53 (p53S) and STICs should be performed to determine whether or not differential PR isoform expression may be involved in high-grade serous carcinoma development. ${ }^{9}$

In this study, we assessed the immunohistochemical profile of FTs and CICs along with the expression of ER- $\alpha$, progesterone receptor A (PRA), Ki-67, p53, and apoptosis, and investigated the effect of menopause on hormonal receptors, proliferation, apoptosis, and presence of $\mathrm{p} 53 \mathrm{~S}$ in FTs in comparison with CICs of the ovary.

\section{Materials and methods}

\section{Case selection}

Eighty-four specimens of AFTs, obtained by conventional tubal sampling of macroscopically normal FTs, were retrieved from the database of the Pathology Department at the University of Occupational and Environmental Health Hospital between 2011 and 2012.

Among 26 premenopausal women, surgical specimens of AFTs were collected from 8 women with invasive cervical cancer, 7 with ectopic pregnancy, 5 with endometrial cancer, 3 with benign ovarian cyst, and 3 with ovarian cancer.

Among 58 postmenopausal women, surgical specimens of AFT were collected from 25 women with benign ovarian cyst, 18 with endometrial cancer, 6 with cervical cancer or dysplasia, 4 with ovarian cancer, 3 with benign uterine tumor, and 2 with peritoneal cancer. The postmenopausal women aged 60 years or older were included in the present study with a reference to age of menopause in medical records. No woman received hormones for the management of menopausal symptoms.

Sixteen of the 84 FTs, which were obtained from 8 premenopausal and 8 postmenopausal women, were able to be examined for both the ampullae and fimbriae. The CICs obtained from the simultaneously resected ovaries of 27 postmenopausal women were also included in this study.

The study was approved by the Review Board of the University Hospital of Occupational and Environmental Health on Ethical Issues (H27-185). The patients whose specimens were used in this study provided written, informed consent for the future use of the specimens for research.

\section{Immunohistochemistry}

For the immunohistochemical analyses, $4-\mu \mathrm{m}$-thick sections were cut from formalin-fixed paraffin-embedded tissue blocks, deparaffinized in xylene, and rehydrated through sequential washes of alcohol and distilled water. Ki-67 and p53 were detected using ready-to-use monoclonal antibodies against Ki-67 and p53 (clones MIB-1 and DO-7, respectively; Dako Cytomation, Kyoto, Japan). ER- $\alpha$ and PRA were detected using monoclonal antibodies (clone 6F11, diluted 1:50, and clone 16, diluted 1:50, respectively; Novocastra, Fukuoka, Japan). ER- $\alpha$ and PRA are essential for the endometrium to proliferate, remodel, and shed in response to estrogen and progesterone. ${ }^{2}$ The immunoreactivity of these antibodies was well established in the literature. The slides were heated in an autoclave at $120^{\circ} \mathrm{C}$ for $5 \mathrm{~min}$ in $0.01 \mathrm{M}$ citrate buffer $(\mathrm{pH}$ $6.0)$ before immunostaining. The slides were incubated with the above-mentioned antibodies for $2 \mathrm{~h}$ at room temperature. Antibody binding was visualized using the EnVision+ Dual link system and diaminobenzidine as a chromogen (Dako Cytomation). The slides were counterstained with methyl green or hematoxylin and mounted.

\section{Detection of apoptosis}

3'-End-labeling of apoptotic cell DNA was performed using an Apop Tag in situ apoptosis detection kit (Millipore Corporation, Tokyo, Japan) in accordance with the manufacturer's instructions. Deparaffinized sections were pretreated with proteinase K for $15 \mathrm{~min}$ at room temperature and treated with methanol containing $3 \% \mathrm{H}_{2} \mathrm{O}_{2}$ for $5 \mathrm{~min}$, for endogenous peroxidase blockage. After applying $75 \mu \mathrm{L} / 5 \mathrm{~cm}^{2}$ of equilibration buffer for $30 \mathrm{~min}$ at room temperature, $55 \mu \mathrm{L} / 5 \mathrm{~cm}^{2}$ of working strength TdT enzyme was pipetted onto sections and incubated in a humidified chamber at $37^{\circ} \mathrm{C}$ for $1 \mathrm{~h}$. After applying working strength stop/wash buffer for $10 \mathrm{~min}, 65 \mu \mathrm{L} / 5 \mathrm{~cm}^{2}$ anti-digoxigenin peroxidase conjugate was pipetted onto each slide, and the slides were incubated in a humidified chamber for $30 \mathrm{~min}$ at room temperature. After washing with phosphate-buffered saline, peroxidase was visualized by diaminobenzidine.

The interpretation of the immunohistochemical preparations was performed and the presence of apoptotic cells was confirmed with the help of the WinROOF image processing software program (Mitani Corp., Tokyo, Japan). ${ }^{1}$

\section{The $\mathrm{p} 53$ signature}

p53S was defined as the presence of endometrial epithelial cells, with either glandular or surface growth patterns, that were morphologically benign in appearance but displayed 12 or more consecutive epithelial cell nuclei with strong p53 immunostaining. ${ }^{5}$ 
Table I Clinicopathological data of the ampullae of the fallopian tube

\begin{tabular}{|c|c|c|c|}
\hline \multirow[t]{2}{*}{ Variable } & \multicolumn{2}{|c|}{ Ampullae of the fallopian tube } & \multirow[t]{2}{*}{$P$-value } \\
\hline & Premenopausal & Postmenopausal & \\
\hline Number of cases & 26 & 58 & \\
\hline Age (years; mean $\pm S D$ ) & $37.3 \pm 7.7$ & $71.0 \pm 7.7$ & $<0.001$ \\
\hline LI for p53 (\%) & $2(0-28)$ & $2(0-12)$ & 0.163 \\
\hline LI for Ki-67 (\%) & $6(I-42)$ & $2(0-2 I)$ & $<0.001$ \\
\hline LI for apoptosis (\%) & I (0-3) & $0(0-2)$ & 0.03 \\
\hline LI for ER- $\alpha(\%)$ & $83(0-96)$ & $88(0-98)$ & 0.1 \\
\hline LI for PRA (\%) & $98(8-99)$ & $12(0-98)$ & $<0.001$ \\
\hline
\end{tabular}

Abbreviations: ER, estrogen receptor; LI, labeling index; PRA, progesterone receptor $\mathrm{A} ; \mathrm{SD}$, standard deviation.

\section{Statistical analyses}

Statistical analyses were carried out using the SPSS software program for Windows, version 22.0.0 (SPSS, Chicago, IL, USA). Data for the clinicopathological factors and immunohistochemical markers were evaluated using the chi-squared test or Mann-Whitney $U$-test. The mean age of the patients was assessed using Student's $t$-test. Spearman's rank correlation coefficient was used to determine the correlations between the immunohistochemical markers. Poisson regression analyses were used to examine the association of $\mathrm{p} 53$, ER- $\alpha$, PRA, and Ki-67 with apoptosis. A value of $P<0.05$ was considered statistically significant.

\section{Results}

\section{Clinicopathological and immunohistochemical findings}

The immunohistochemical data for premenopausal and postmenopausal AFTs are presented in Table 1. Although premenopausal AFTs were collected in women with varied diseases, the labeling index (LI) for ER- $\alpha$ and PRA in premenopausal AFTs was consistently high regardless of the menstrual cycle or ectopic pregnancy (Figure 1). Postmenopausal AFTs showed significantly lower LI for Ki-67 $(P<0.001)$, apoptosis $(P=0.03)$, and PRA $(P<0.001)$ than premenopausal AFTs, whereas the LIs for p53 and ER- $\alpha$ showed no significant difference between premenopausal and postmenopausal AFTs. In the univariate analysis, the LI for apoptosis was inversely correlated with the menopausal status $(P=0.021)$ and significantly correlated with PRA $(P=0.005)$, whereas multivariate analyses showed that no variables were correlated with apoptosis (Table 2). No significant correlation among the immunohistochemical markers was found in premenopausal AFTs, whereas the LI for PRA was significantly correlated with those for Ki-67 $(P=0.004, r=0.373)$ and p53 $(P=0.023, r=-0.298)$ in postmenopausal AFTs. An LI for PRA of $90 \%$ or more was found in $8(13.8 \%)$ of 58 postmenopausal AFTs and in 24 of 26 (92.3\%) premenopausal AFTs. Among 16 FTs examined for both ampullae and fimbriae, the expressions of p53, Ki-67, apoptosis, ER- $\alpha$, and PRA (Figure 2) were significantly correlated between the ampullae and fimbriae ( $r=0.564: P=0.023 ; r=0.602: P=0.016 ; r=0.556: P=0.025$; $r=0.487: P=0.011$; and $r=0.956: P<0.001$, respectively).

The immunohistochemical data of the p53S are presented in Table 3. The p53S was positive in $5(12.7 \%)$ of 58 postmenopausal AFTs (Figure 3) and negative in 26 premenopausal AFTs and 16 fimbriae. The mean age of women with p53S positivity was 70.2 years. The immunohistochemical profile of $\mathrm{p} 53 \mathrm{~S}$ was not markedly different from that of postmenopausal AFTs with a background of p53S.
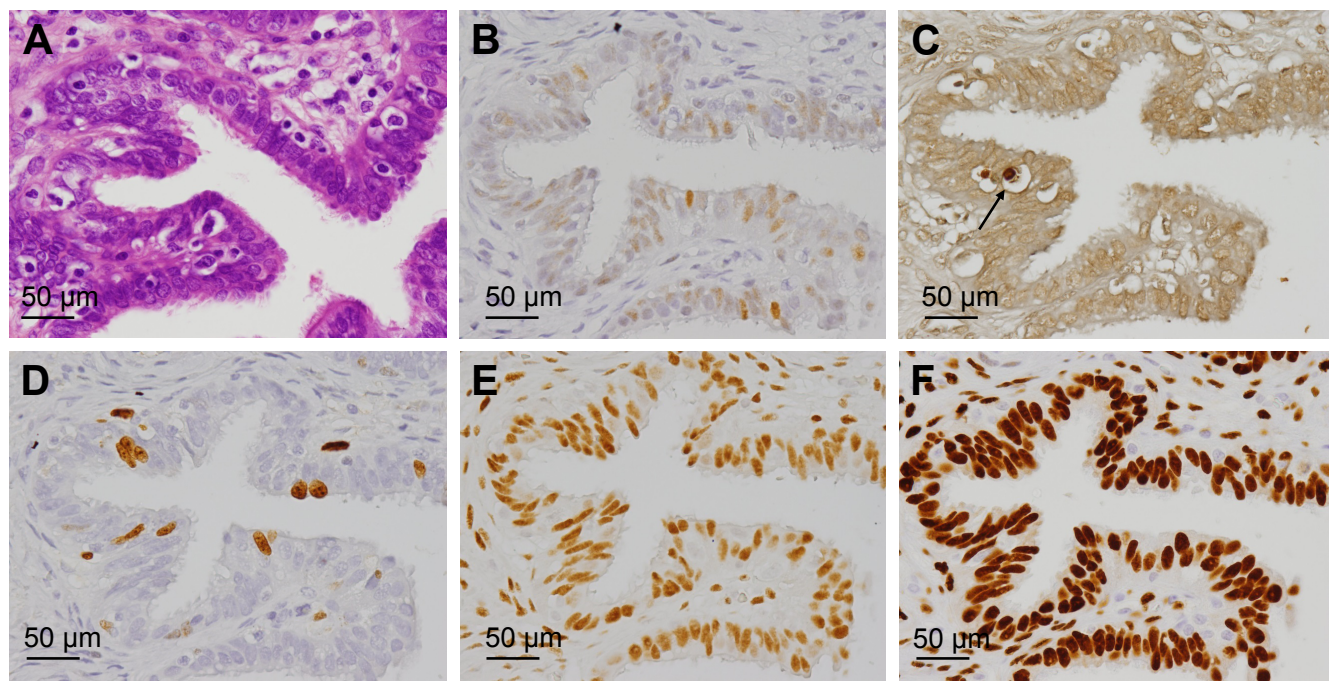

Figure I The ampullae of the fallopian tube in a 32-year-old woman with ectopic pregnancy (A). Moderate-to-strong expression of p53 is shown in the epithelial cells, but the staining pattern is not enough to be labeled p53 signature (B). The apoptotic body (C; arrow) and mild proliferative activity for Ki-67 (D) are shown. Positivity for estrogen receptor-alpha $(\mathbf{E})$ and progesterone receptor $A(\mathbf{F})$. All figures are presented at $40 \times$ original magnification. 
Table 2 Incidence rate ratios for the expression of apoptotic cells in the ampullae of the fallopian tube

\begin{tabular}{|c|c|c|c|c|c|c|}
\hline \multirow[t]{2}{*}{ Variable } & \multicolumn{3}{|c|}{ Univariate } & \multicolumn{3}{|c|}{ Multivariate } \\
\hline & IRR & $95 \% \mathrm{Cl}$ & $P$-value & IRR & $95 \% \mathrm{Cl}$ & $P$-value \\
\hline Menopause & 0.51 & $0.29-0.09$ & 0.021 & 0.93 & $0.4 I-2.08$ & $0.85 I$ \\
\hline p53 & 1.03 & $0.99-1.08$ & 0.148 & 1.02 & $0.97-1.07$ & 0.392 \\
\hline $\mathrm{Ki}-67$ & 1.03 & $1.00-1.06$ & 0.066 & 1.01 & $0.97-1.04$ & 0.769 \\
\hline ER- $\alpha$ & 1.01 & $0.99-1.03$ & 0.473 & 1.01 & $0.99-1.03$ & 0.475 \\
\hline PRA & 1.01 & $1.00-1.02$ & 0.005 & 1.01 & $1.00-1.02$ & 0.068 \\
\hline
\end{tabular}

Abbreviations: $\mathrm{Cl}$, confidence interval; $\mathrm{ER}$, estrogen receptor; IRR, incidence rate ratio; PRA, progesterone receptor $A$.

The mean age \pm standard deviation (SD) of women with $\mathrm{CIC}$ was $71.0 \pm 7.7$ years. Twenty-seven of the CIC specimens were immunohistochemically examined. The median and range of the LI for p53, Ki-67, apoptosis, ER- $\alpha$, and PRA were $0 \%$ and $0 \%-5 \%, 2 \%$ and $0 \%-5 \%, 0 \%$ and $0 \%-1 \%$, $70 \%$ and $0 \%-98 \%$, and $92 \%$ and $0 \%-100 \%$, respectively. Compared with AFTs, CICs had significantly lower LIs for p53 $(P<0.001)$, apoptosis $(P=0.003)$, and ER- $\alpha(P<0.001)$ and higher LI for PRA ( $P=0.001$ ) (Figure 4$)$. p53S was not detected in 27 CICs.

\section{Discussion}

Although we were unable to find any studies of age-related changes in the expression of hormone receptors in the FTs in the literature, the expression of PRA was significantly decreased in postmenopausal AFTs compared with premenopausal AFTs, whereas the expression of ER- $\alpha$ was well preserved in both premenopausal and postmenopausal AFTs. Regarding the expression of Ki-67 in FTs, younger groups (45-50 years) reportedly showed higher proliferation than older groups (51-55 years), but this difference was not statistically significant. ${ }^{10}$ In the present study, postmenopausal AFTs (ranging in age from 60 to 86 years) showed significantly lower LIs for Ki-67 than premenopausal AFTs (ranging in age from 21 to 47 years). The expression of PRA was positively correlated with that of Ki-67 and inversely correlated with that of p53 in postmenopausal AFTs.

Although ER- $\alpha$ was reported not to be detected in the FT of women with ectopic pregnancy, ${ }^{11}$ the LI for ER- $\alpha$ was consistently high in AFTs of women with ectopic pregnancy in the present study.

Ovarian high-grade serous carcinomas have been well known to show high expression of ER and low expression of PR. ${ }^{9} 12$ The expression of hormone receptors in postmenopausal AFTs had a similar feature as that of hormone receptors of ovarian high-grade serous carcinoma, while that of hormone receptors of CICs had an inverse feature. The strong expression of $\mathrm{PR}$ was reported to be a good prognostic indicator in ovarian high-grade serous carcinoma. ${ }^{12}$ The increased expression of PR was reported in the CIC of patients with a hereditary predisposition compared with controls. ${ }^{13}$
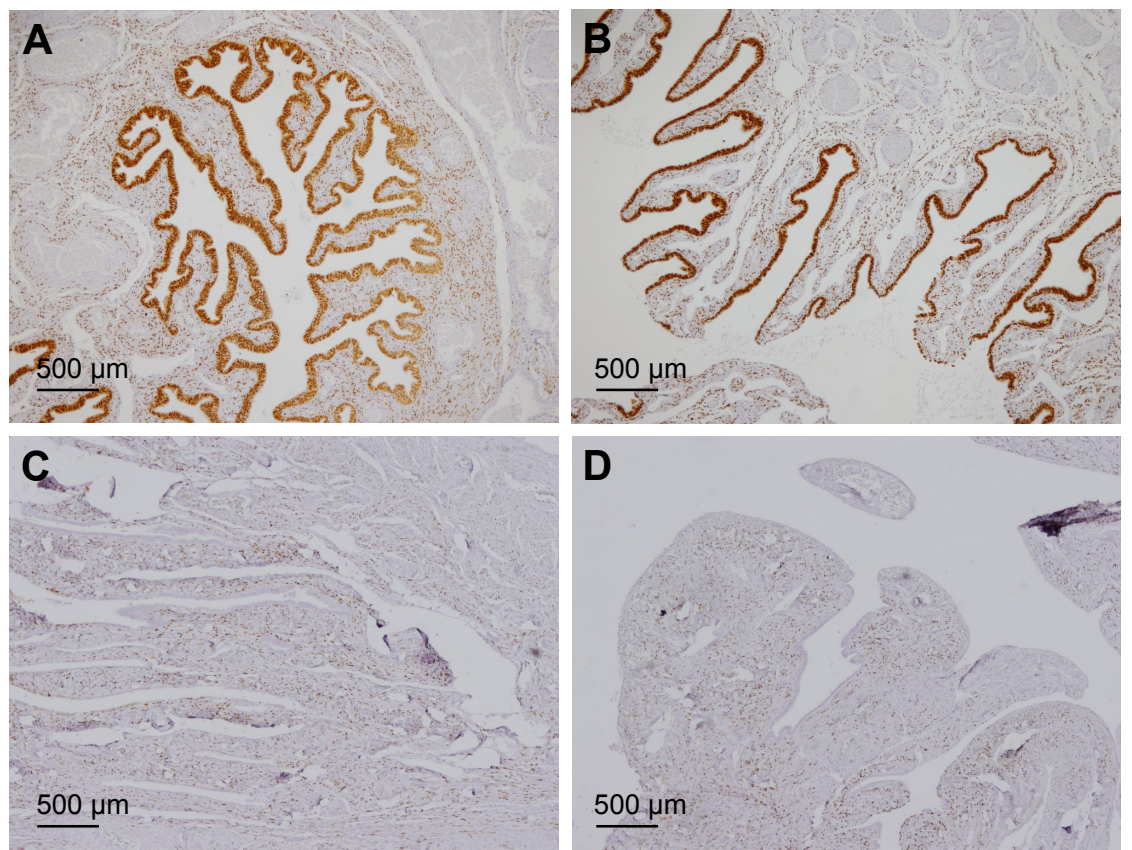

Figure 2 Ampullae (A) and the fimbriated end (B) show positivity for progesterone receptor A in a 31 -year-old woman with cervical carcinoma. Ampullae (C) and the fimbriated end (D) show negativity for progesterone receptor $A$ in an 85 -year-old woman with endometrial carcinoma. All figures are presented at $4 \times$ original magnification. 
Table 3 Immunohistochemical profile of the p53 signature in the ampullae of the fallopian tube

\begin{tabular}{lllllll}
\hline Case & Age (years) & Disease & Ki-67 (\%) & ER- $\alpha$ (\%) & PRA (\%) & Apoptosis (\%) \\
\hline 1 & 75 & Endometrial cancer & 0 & 100 & 0 & 0 \\
2 & 80 & Serous cyst & 0 & 27 & 0 & 0 \\
3 & 64 & Mucinous cyst & 0 & 100 & 2 & 0 \\
4 & 77 & Endometrial cancer & 3 & 91 & 15 & 0 \\
5 & 76 & Endometrial cancer & 0 & 100 & 0 & 0 \\
\hline
\end{tabular}

Abbreviations: ER, estrogen receptor; PRA, progesterone receptor A.

Ovarian high-grade serous carcinoma is closely related to advanced age of patients, with a reported mean age of 63 years. ${ }^{6}$ In the nonprophylactic setting, Morrison et a ${ }^{14}$ and Gilks et al ${ }^{15}$ reported respective mean ages of 62.7 and 57 years among patients with STIC. Under non-neoplastic conditions of the FT, the incidence of STIC was also associated with advanced patient age. ${ }^{16}$ STIC is commonly located in the tubal fimbria and is associated with $\mathrm{p} 53 \mathrm{~S} .{ }^{17}$ However, p53S was reported to be equally prevalent in FTs of BRCA mutation carriers and controls, with no particular association with age. ${ }^{18,19}$ p53S of AFTs was only found in elderly women (mean age; 70.2 years) in the present study. We previously examined the overexpression of $\mathrm{p} 53$ in normal endometriums, ${ }^{1}$ endometrial polyps, ${ }^{20}$ and the background endometrium of endometrial carcinomas. ${ }^{21}$ Our previous studies showed that endometrial $\mathrm{p} 53 \mathrm{~S}$ was closely related with advanced patient age, except in patients with Lynch syndrome. The postmenopausal endometrial glands have been consistently reported to be positive for ER- $\alpha$ and PRA. ${ }^{1,2}$ The incidence of p53S (12.7\%) in postmenopausal AFTs was almost the same as that of $\mathrm{p} 53 \mathrm{~S}(11.1 \%)$ in postmenopausal endometrial glands. ${ }^{1}$ High proliferative activity with low apoptotic cell death was shown in the postmenopausal endometrial glands surrounded $\mathrm{p} 53 \mathrm{~S},{ }^{1}$ but the immunohistochemical profile of fallopian tubal $\mathrm{p} 53 \mathrm{~S}$ was not markedly different from that of postmenopausal AFTs on a background of $\mathrm{p} 53 \mathrm{~S}$.

A previous study of carcinoma of the FT showed that $92 \%$ of the tumors were situated within the tubal portion of the organ, most often in its distal two-thirds, and $8 \%$ of the tumors were confined to the fimbriae. ${ }^{22}$ However, the adoption of the sectioning and extensively examining the fimbriated end (SEE-FIM) protocol have led to increased awareness of tubal fimbriae as a source of high-grade serous carcinomas. ${ }^{23}$ The immunohistochemical markers in the present study were unable to reveal a significant difference between the ampullae and fimbriae of the FTs. As such, differences between carcinoma of the ampullae and fimbriae of the FT should be examined in future studies.

\section{Conclusion}

The decreased expression of PRA was found in postmenopausal AFTs and was significantly associated with a low
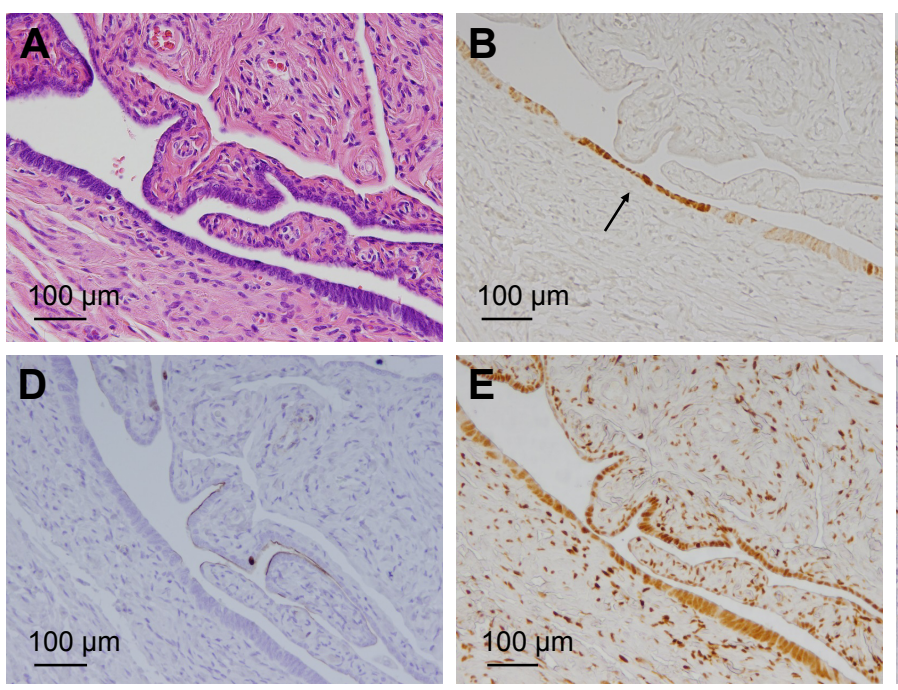
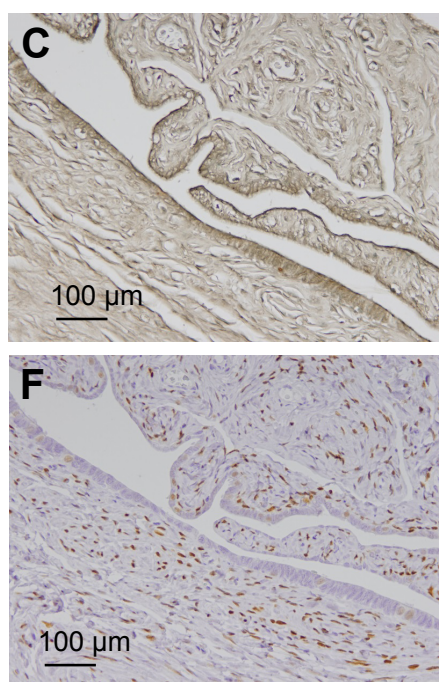

Figure 3 Case 2: The ampullae of the fallopian tube in a 75-year-old woman with ovarian serous cystadenoma (A). p53 signature (p53S) is shown (B; arrow). $\mathrm{p} 53 \mathrm{~S}$ shows negativity for apoptosis (C), Ki-67 (D), and progesterone receptor A (F), and positivity for estrogen receptor-alpha (E). All figures are presented at 20× original magnification. 

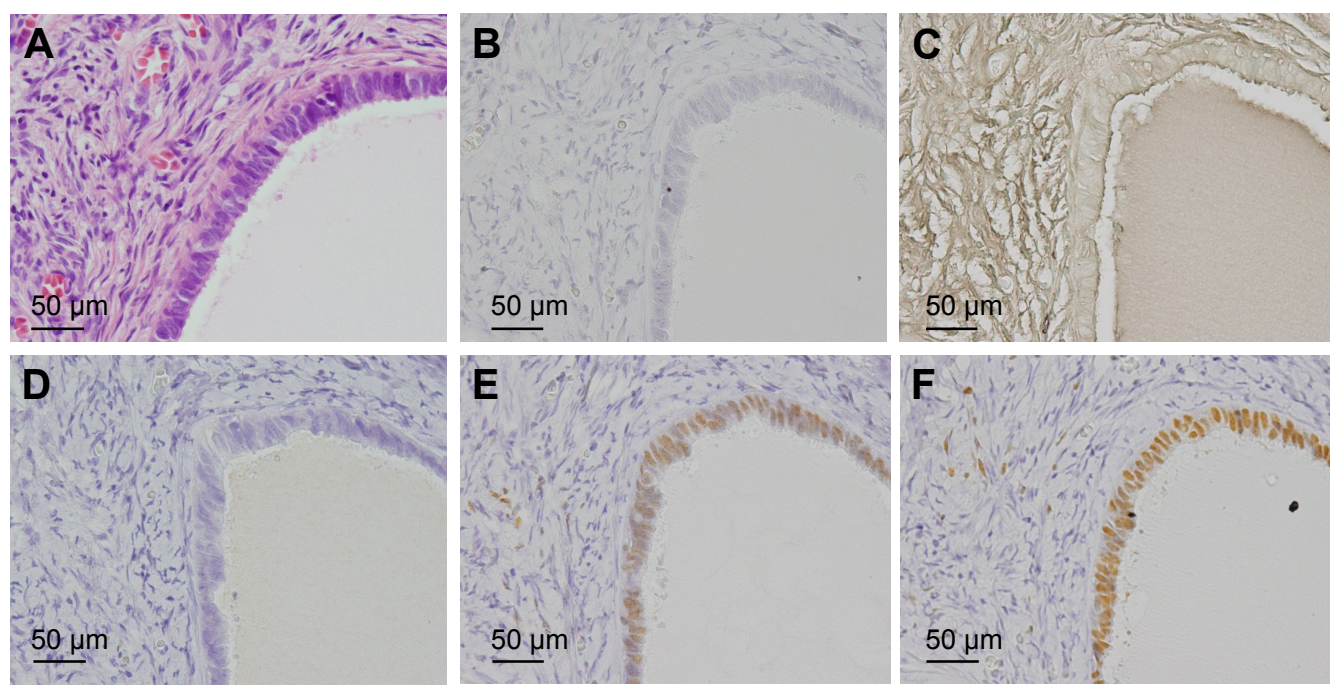

Figure 4 Ovarian cortical inclusion cyst in the left normal looking ovary in a 68-year-old woman with right ovarian serous cystadenoma (A). The epithelial cells show negativity for $\mathrm{p} 53$ (B), apoptosis (C), and Ki-67 (D), and positivity for estrogen receptor-alpha (E) and progesterone receptor A (F). All figures are presented at 40× original magnification.

proliferative and apoptotic index but was not associated with changes in the expression of ER- $\alpha$. The expression pattern of PRA and ER- $\alpha$ in postmenopausal AFTs is similar to that in ovarian high-grade serous carcinoma and inversely correlated with that in CICs.

\section{Disclosure}

The authors report no conflicts of interest in this work.

\section{References}

1. Koi C, Hachisuga T, Murakami M, et al. Overexpression of p53 in the endometrial gland in postmenopausal women. Menopause. 2015;22(1): 104-107.

2. Mylonas I, Jeschke U, Shabani N, et al. Steroid receptors ER $\alpha$, ER $\beta$, PR-A and PR-B are differentially expressed in normal and atrophic human endometrium. Histol Histopathol. 2007;22(2):169-176.

3. Udou T, Hachisuga T, Tsujioka H, Kawarabayashi T. The role of c-Jun protein in proliferation and apoptosis of the endometrium throughout the menstrual cycle. Gynecol Obstet Invest. 2004;57(3):121-126.

4. Taylor LJ, Jackson TL, Reid JG, Duffy SR. The differential expression of oestrogen receptors, progesterone receptors, Bcl-2 and Ki67 in endometrial polyps. BJOG. 2003;110(9):794-798.

5. Folkins AK, Jarboe EA, Saleemuddin A, et al. A candidate precursor to pelvic serous cancer (p53 signature) and its prevalence in ovaries and fallopian tubes from women with heterozygous BRCA mutations. Gynecol Oncol. 2008;109(2):168-173.

6. Longacre TA, Wells M. Serous tumours. In: Kurman RJ, Carcangiu ML, Herrington S, Young RH, editors. WHO Classification of Tumours of Female Reproductive Organs. Switzerland: WHO Press; 2014:15-24.

7. Crum CP, McKeon FD, Xian W. BRCA, the oviduct, and the space and time continuum of pelvic serous carcinogenesis. Int J Gynecol Cancer. 2012; 22 (Suppl 1):S29-S34.

8. Tone AA, Begley H, Sharma M, et al. Gene expression profiles of luteal phase fallopian tube epithelium from BACA mutation carrier resemble high-grade serous carcinoma. Clin Cancer Res. 2008;14(13): $4067-4078$
9. Tone AA, Virtanen C, Shaw PA, Brown TJ. Decreased progesterone receptor isoform expression in luteal phase fallopian tube epithelium and high-grade serous carcinoma. Endocr Relat Cancer. 2011;18(2): 221-234.

10. George Sophia HL, Milea A, Shaw PA. Proliferation in the normal FTE is a hallmark of the follicular phase, not BRCA mutation status. Clin Cancer Res. 2012;18(22):6199-6207.

11. Horne AW, King AE, Shaw E, et al. Attenuated sex steroid receptor expression in Fallopian tube of women with ectopic pregnancy. J Clin Endocrinol Metab. 2009;94(12):5146-5154.

12. Sieh W, Köbel M, Longacre TA, et al. Associations between hormone receptor expression and ovarian cancer survival: an ovarian tumor tissue analysis consortium study. Lancet Oncol. 2013;14(9):853-862.

13. Piek JM, Verheijen RH, Menko FH, et al. Expression of differentiation and proliferation related proteins in epithelium of prophylactically removed ovaries from women with a hereditary female adnexal cancer predisposition. Histopathology. 2003;43(1):26-32.

14. Morrison JC, Blanco LZ Jr, Vang R, Ronnett BM. Incidental serous tubal intraepithelial carcinoma and early invasive serous carcinoma in the nonprophylactic setting: analysis of a case series. Am J Surg Pathol. 2015;39(4):442-453.

15. Gilks CB, Irving J, Köbel M, et al. Incidental nonuterine high-grade serous carcinomas arise in the fallopian tube in most cases: further evidence for the tubal origin of high-grade serous carcinomas. Am J Surg Pathol. 2015;39(3):357-364.

16. Seidman JD, Krishnan J, Yemelyanova A, Vang R. Incidental serous tubal intraepithelial carcinoma and non-neoplastic conditions of the fallopian tubes in grossly normal adnexa: a clinicopathologic study of 388 completely embedded cases. Int J Gynecol Pathol. 2016;35(5):423-429.

17. Lee Y, Miron A, Drapkin R, et al. A candidate precursor to serous carcinoma that originates in the distal fallopian tube. J Pathol. 2007;211(1): 26-35.

18. Cass I, Walts AE, Barbuto D, Lester J, Karlan B. A cautious view of putative precursors of serous carcinomas in the fallopian tubes of BRCA mutation carriers. Gynecol Oncol. 2014;134(3):492-497.

19. Mehra KK, Chang MC, Folkins AK, et al. The impact of tissue block sampling on the detection of $\mathrm{p} 53$ signatures in fallopian tubes from women with BRCA 1 or 2 mutations (BRCA+) and controls. Mod Pathol. 2011;24(1):152-156. 
20. Sho T, Hachisuga T, Kawagoe T, et al. Expression of p53 in endometrial polyps with special reference to p53 signature. Histol Histopathol. 2016; 31(7):751-758.

21. Nguyen TT, Hachisuga T, Urabe R, et al. Significance of p53 expression in background endometrium in endometrial carcinoma. Virchows Arch. 2015;466(6):695-702.

22. Alvarado-Cabrero I, Young RH, Vamvakas EC, Scully RE. Carcinoma of the fallopian tube: a clinicopathological study of 105 cases with observations on staging and prognostic factors. Gynecol Oncol. 1999;72(3): 367-379.
23. Singh N, Gilks CB, Hirschowitz L, et al. Primary site assignment I tubo-ovarian high-grade serous carcinoma: consensus statement on unifying practice worldwide. Gynecol Oncol. 2016;141(2):195-198.

International Journal of Women's Health

\section{Publish your work in this journal}

The International Journal of Women's Health is an international, peerreviewed open-access journal publishing original research, reports, editorials, reviews and commentaries on all aspects of women's healthcare including gynecology, obstetrics, and breast cancer. The manuscript management system is completely online and includes a very quick and fair peer-review system, which is all easy to use. Visit http://www.dovepress.com/testimonials.php to read real quotes from published authors.

Submit your manuscript here: http://www.dovepress.com/international-journal-of-womens-health-journal 